\title{
Roux-en-Y gastric bypass surgery suppresses hypothalamic PTP1B protein level and alleviates leptin resistance in obese rats
}

\author{
JIA-YU LIU ${ }^{1 *}$, SONG MU ${ }^{2 *}$, SHU-PING ZHANG ${ }^{1}$, WEI GUO ${ }^{2}$, QI-FU LI ${ }^{1}$, \\ XIAO-QIU XIAO ${ }^{3}$, JUN ZHANG ${ }^{2}$ and ZHI-HONG WANG ${ }^{1}$ \\ Departments of ${ }^{1}$ Endocrinology and ${ }^{2}$ General Surgery; ${ }^{3}$ Laboratory of Lipid and Glucose Metabolism, \\ The First Affiliated Hospital of Chongqing Medical University, Chongqing 400016, P.R. China
}

Received March 6, 2016; Accepted February 13, 2017

DOI: $10.3892 / \mathrm{etm} .2017 .4801$

\begin{abstract}
The present study aimed to explore the effect of Roux-en-Y gastric bypass (RYGB) surgery on protein tyrosine phosphatase 1B (PTP1B) expression levels and leptin activity in hypothalami of obese rats. Obese rats induced by a high-fat diet (HFD) that underwent RYGB $(n=11)$ or sham operation $(\mathrm{SO}, \mathrm{n}=9)$, as well as an obese control cohort (Obese, $\mathrm{n}=10)$ and an additional normal-diet group (ND, n=10) were used. Food efficiency was measured at 8 weeks post-operation. Plasma leptin levels were evaluated and hypothalamic protein tyrosine phosphatase 1B (PTP1B) levels and leptin signaling activity were examined at the genetic and protein levels. The results indicated that food efficiency was typically lower in RYGB rats compared with that in the Obese and SO rats. In the RYGB group, leptin receptor expression and proopiomelanocortin was significantly higher, while Neuropeptide Y levels were lower than those in the Obese and SO groups. Furthermore, the gene and protein expression levels of PTP1B in the RYGB group were lower, while levels of phosphorylated signal transducer and activator of transcription 3 protein were much higher compared with those in the Obese and SO groups. In conclusion, RYGB surgery significantly suppressed hypothalamic PTP1B protein expression. PTP1B regulation may partially alleviate leptin resistance.
\end{abstract}

Correspondence to: Dr Zhi-Hong Wang, Department of Endocrinology, The First Affiliated Hospital of Chongqing Medical University, 1 Youyi Road, Chongqing 400016, P.R. China

E-mail: towzh723@sina.com

Dr Jun Zhang, Department of General Surgery, The First Affiliated Hospital of Chongqing Medical University, 1 Youyi Road, Chongqing 400016, P.R. China

E-mail: junzzhe23@sina.com

*Contributed equally

Key words: Roux-en-Y gastric bypass surgery, obesity, hypothalamus, protein tyrosine phosphatase $1 \mathrm{~B}$, leptin

\section{Introduction}

Obesity and its comorbidities are public health concerns that are increasing at pandemic proportions (1). The marked increase in obesity is impacting the global incidence of chronic disease and mortality (2). Obesity is traditionally treated with lifestyle modifications and drugs; however, these methods have limited success. At present, bariatric surgery is the most effective treatment for morbid obesity $(3,4)$. Various types of bariatric surgical options have been developed over the past 50 years. Roux-en-Y gastric bypass (RYGB) surgery is the most commonly performed surgery for morbid obesity $(5,6)$.

RYGB effectively reduces body weight and alleviates or even reverses obesity-associated comorbidities (7). It is the most commonly performed weight loss operation $(8,9)$. Certain patients have increased satiety and decreased hunger post-operation (10). Various mechanisms of how RYGB causes weight loss have been postulated, while the exact mechanism requires to be fully elucidated. Of particular interest is the impact of RYGB on the hypothalamus, which is a critical area involved in energy balance regulation and integration of peripheral hormonal signals to regulate energy intake and expenditure.

Leptin is an important peripheral hormone for energy regulation that is encoded by the $O B$ gene and is secreted by fat cells. Leptin exerts its action by binding to and activating leptin receptors (Lep-R) to active the Janus kinase (JAK)/signal transducer and activator of transcription (STAT) signaling pathway in the hypothalamus (11-13). The hypothalamus contains various distinct leptin-responsive neuronal populations. Proopiomelanocortin (POMC) neurons produce the anorectic peptide $\alpha$-melanocyte-stimulating hormone ( $\alpha$-MSH) and act via the melanocortin 3/4 receptors (MC3/4-Rs). A separate neuronal population in the hypothalamus expresses two orexigenic peptides, the melanocortin receptor antagonist agouti-related protein (AgRP) and neuropeptide Y (NPY), which are thought to be key mediators of leptin action (14). Activated JAK/STAT signaling improves $\alpha$-MSH and suppresses AgRp and NPY expression levels to reduce food intake and promote energy expenditure to maintain energy homeostasis and body weight. Protein tyrosine phosphatase 1B (PTP1B) is an important negative regulator of leptin and insulin signaling and has been implicated in the development of 
cellular leptin and insulin resistance (15). PTP1B is a member of the PTP family and is encoded by the PTPN1 gene (16), which is abundantly and ubiquitously expressed (e.g., in the hypothalamus). PTP1B is localized on the cytoplasmic face of the endoplasmic reticulum (17). PTP1B has a role in multiple pathways by dephosphorylating the tyrosine residues of several proteins, such as insulin receptor substrate-1 (IRS-1) and JAK2 $(18,19)$. PTP1B levels have been reported to be elevated in the muscle, liver and hypothalamus of obese rodents (20). High levels of PTP1B protein are associated with hyperphagia, leptin residence and obesity (21). Furthermore, mice with hypothalamus-specific deficiency of PTP1B are resistant to diet-induced obesity caused by leptin hypersensitivity (22). Based on these findings, PTP1B may be involved in the onset of leptin resistance. Hao et al (23) found that in leptin-deficient ob/ob mice, RYGB does not induce weight loss. Their study suggested that leptin critically influences weight reduction after RYGB. In addition, in most obese individuals, circulating leptin levels are abnormally upregulated and this upregulation is thought to impair leptin sensitivity (24). However, other studies demonstrated that leptin levels were decreased after RYGB $(25,26)$. Together, these findings suggested that RYGB may restore leptin sensitivity and partially contributes to the sustainable weight loss and resolution of obesity-associated conditions.

However, the exact mechanisms of the effect of RYGB surgery have remained to be fully clarified and few studies have investigated changes in PTP1B after RYGB. In the present study, it was hypothesized that RYGB improves leptin sensitivity in the hypothalamus, involving the suppression PTP1B levels to partially achieve a state of energy homeostasis. A rat model of obesity was used to experimentally verify this hypothesis.

\section{Materials and methods}

Animals and diet. Male 4-week-old Sprague Dawley rats ( $\mathrm{n}=70$; body weight, $101.2 \pm 12.3 \mathrm{~g}$ ) were obtained from the animal center of Chongqing Medical University (Chongqing, China). The animals were housed with a 12 -h artificial light-dark cycle at $22 \pm 2^{\circ} \mathrm{C}$ with $60 \%$ humidity. The rats had free access to food and tap water. After 1 week of adaptive feeding, the rats were randomly divided into two groups: A standardized diet (cat. no. D12450B; $3.85 \mathrm{kcal} / \mathrm{g}, 10 \%$ from fat; Research Diets, New Brunswick, NJ, USA) was provided for the lean control $(n=10)$. In the other group $(n=60)$ a high-fat diet (cat. no. D12451; $4.73 \mathrm{kcal} / \mathrm{g}$, 45\% from fat; Research Diets) was provided to induce obesity as a model of human obesity. After 12 weeks, 30 rats were successfully established as obesity models. The other rats were removed because they did not meet the criteria of the obesity model. These rats were anesthetized using $10 \%$ chloral hydrate $(0.5 \mathrm{ml} / 100 \mathrm{~g})$, then $3 \mathrm{ml}$ of blood was collected by puncture of the right atrium. Finally, the rats were sacrificed by an injection of air into the heart. The diet-induced obese rats $(n=30)$ were divided into 3 groups as follows: RYGB $(n=11)$, sham operation $(\mathrm{SO}, \mathrm{n}=9)$, obese control cohort (obese, $\mathrm{n}=10$ ) and an additional normal $\operatorname{diet}(\mathrm{ND}, \mathrm{n}=10)$, intact group of rats (no surgery) was included. Body weight was recorded weekly and rats in the HFD group who weighed at least $20 \%$ more than the normal control rats were considered to be obese. Food efficiency was calculated at 8 weeks post-operation. Eight weeks later, the hypothalamic and blood samples were harvested after the rats were sacrificed (the rats were anesthetized using 10\% chloral hydrate $(0.5 \mathrm{ml} / 100 \mathrm{~g})$, then $3 \mathrm{ml}$ of blood was collected by puncture of the right atrium). The rats were sacrificed by an injection of air into the heart. Plasma leptin levels were measured and hypothalamic PTP1B and leptin signaling activity was examined at the mRNA and protein level. The protocol of the present study was approved by the ethics committee of Chongqing Medical University (Chongqing, China) and followed the Chinese Guidelines for the Use of Animals in Experimental Studies.

Surgical procedures. To induce obesity, the rats were fed a high-fat diet for 12 weeks, and the diet-induced obese rats weighed $510.1 \pm 8.316 \mathrm{~g}$. Before the operation, rats were fasted for $12 \mathrm{~h}$ with unrestricted access to water. For the RYGB procedure, the stomach was transected close to the gastroesophageal junction to create a small gastric pouch and the stump of the stomach was closed with 6-0 sutures. The jejunum was cut at $15 \mathrm{~cm}$ distal to the ligament of Treitz and an anastomosis was performed between the distal jejunum and esophagus. An enterotomy was performed at $10 \mathrm{~cm}$ distal to the esophagojejunostomy and an anastomosis was created between the enterotomy and the proximal jejunum. The bowel anastomoses were closed with 6-0 silk sutures. For the sham operation, transections were performed in the gastrointestinal tract at the sites where the gastrotomy and enterotomy were performed for RYGB, and reanastomosis was performed at the original transection sites. Body weight and blood glucose levels were recorded weekly after the operation.

Measurement offood intake and food efficiency. Food intake was recorded at 8 weeks after the operation. The rats in the four groups (Lean, Obese, RYGB and SO group) were individually housed in cages. Prior to the measurements, rats were fasted for $12 \mathrm{~h}$ with unrestricted access to water. The rats were each provided a pre-weighed amount of food. Food intake and body weight were recorded at 0,2, 4, 6, 12 and $24 \mathrm{~h}$ after refeeding. Food efficiency was calculated as grams of weight change per kilocalorie of food consumed over the study period.

Reverse-transcription quantitative polymerase chain reaction analysis (RT-qPCR). Total RNA from the hypothalamus was extracted using TRIzol reagent (Takara Bio, Inc., Otsu, Japan), and was converted into complementary (c)DNA using a PrimeScript RT reagent kit (Takara Bio, Inc.). qPCR analysis was performed using SYBR-Green (Bio-Rad Laboratories, Inc., Hercules, CA, USA) in a real-time PCR apparatus (Applied Biosystems; Thermo Fischer Scientific, Inc., Waltham, MA, USA). The primers for RT-qPCR, whose sequences are shown in Table I, were designed and purchased from Takara Bio, Inc. A $20 \mu 1$ total PCR reaction system was used, consisting of $10 \mu 1$ 2x SYBR-Green Mixture (including GoldGtar Taq, DNA polymerase, PCR buffer, dNTPs, SYBR-Green; Takara Bio, Inc.), $1 \mu \mathrm{l}$ forward and $1 \mu 1$ reverse

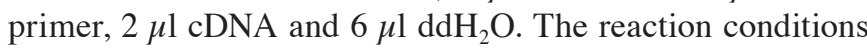
were: $94^{\circ} \mathrm{C}$ denaturing for $5 \mathrm{~min}$, followed by 40 cycles of $94^{\circ} \mathrm{C}$ for $15 \mathrm{sec}$ and $60^{\circ} \mathrm{C}$ for $1 \mathrm{~min}$. PCR was performed on an 
Table I. Sequences of primers used for polymerase chain reaction.

\begin{tabular}{ll}
\hline Name & \multicolumn{1}{c}{ Sequence (5'-3') } \\
\hline PTP1B-F & GAAACGGATGGTGGGTGGA \\
PTP1B-R & CACACGTTGACCAGGAAGGG \\
LEPR-F & GTACCAGTACCCAGAGCC \\
LEPR-R & GACCTCGTATGAAGACCC \\
POMC-F & CCTCCTGCTTCAGACCTCCAT \\
POMC-R & TCAAGGGCTGTTCATCTCCGT \\
NPY-F & CTGCGACACCTACATCAATCT \\
NPY-R & ATACAACGACAACAAGGGA \\
GAPDH-F & CGGAGTCAACGGATTTGGTCGTAT \\
GAPDH-R & AGCCTTCTCCATGGTGGTGAAGAC
\end{tabular}

F, forward; R, reverse; PTP1B, protein tyrosine phosphatase 1B; LepR, leptin receptor, POMC, proopiomelanocortin; NPY, Neuropeptide Y.

ABI GeneAmp 5700 real-time fluorescent quantitative PCR cycler (Applied Biosystems; Thermo Fisher Scientific, Inc.). The $\Delta \Delta \mathrm{Cq}$ method was used to determine the fold change for each group (27). GAPDH was used to normalize the expression of the target genes.

Western blot analysis. Following sacrification, the hypothalamus was excised, immediately frozen in liquid nitrogen and stored at $-80^{\circ} \mathrm{C}$ until processing. For western blot analysis, $80 \mu \mathrm{g}$ of protein extract was separated by $10 \%$ SDS-PAGE and transferred onto polyvinylidene difluoride membranes (Millipore, Billerica, MA, USA). Non-specific binding was blocked by incubating the membranes for $2 \mathrm{~h}$ at room temperature with $5 \%$ milk followed by incubation with the following primary antibodies: Rabbit anti-rat phosphorylated (p)-STAT3 polyclonal antibody (cat. no. 94994; 1:2,000 dilution; Cell Signaling Technology, Inc., Danvers, MA, USA), rabbit anti-rat STAT3 polyclonal antibody (catalogue no. 12640; 1:1,000 dilution; Cell Signaling Technology, Inc.), rabbit anti-rat $\beta$-actin polyclonal antibody (catalogue no. 20536-1-AP; 1:5,000 dilution; Proteintech, Inc., Chicago, IL, USA) and mouse anti-rat PTP1B monoclonal antibody (cat. no. 107AT690; 1;200 dilution; Santa Cruz Biotechnology, Inc., Dallas, TX, USA) overnight at $4^{\circ} \mathrm{C}$. The membranes were then incubated with secondary antibody peroxidase-conjugated Affinipure goat anti-rabbit (Cat. no. 515-005-071; 1:500 dilution) or anti-mouse (cat. no. 715-475-150; 1:500 dilution) immunoglobulin G (both Jackson ImmunoResearch Laboratories, Inc., West Grove, PA, USA) for $1 \mathrm{~h}$ at room temperature. Protein expression was detected using a Western Bright ECL kit (Advansta, Menlo Park, CA, USA). Densitometric analysis was performed using Quantity One software version 4.6.9 (Bio-Rad Laboratories, Inc.).

Analysis of plasma leptin. Blood was collected from a cava vein after anesthesia. Plasma was separated by centrifugation at $2,000 \mathrm{x}$ g for $15 \mathrm{~min}$ at $4^{\circ} \mathrm{C}$ and stored $-80^{\circ} \mathrm{C}$ until analysis. A leptin rat ELISA assay kit (cat. no. KRC2281; HuShang
Biological Technology, Shanghai, China) was utilized to measure plasma leptin.

Statistical analysis. Values are expressed as the mean \pm standard error of the mean. Differences between groups were assessed using one-way analysis of variance and the unpaired Student's t-test. $P<0.05$ was considered to indicate a statistically significant difference. Statistical analyses were performed using GraphPad Prism 5.01 (GraphPad Inc., La Jolla, CA, USA).

\section{Results}

$R Y G B$ reduces body weight and caloric intake, and improves food efficiency. To evaluate the metabolic response during the experiments, the body weight, caloric intake and food efficiency were assessed. The diet-induced obesity model was successfully established. The mean body weight of the RYGB $(512.9 \pm 13.44 \mathrm{~g}), \mathrm{SO}(503.9 \pm 17.83 \mathrm{~g})$ and Obese $(494.0 \pm 8.442 \mathrm{~g})$ groups prior to surgery were similar and the body weight of the Lean group $(393.4 \pm 6.95 \mathrm{~g})$ was lower than that in the other three groups $\mathrm{P}<0.01$. There were no significant changes in body weight immediately after surgery in the RYGB and SO groups. Compared with their pre-surgery weights, weight loss in the RYGB group was maximal at $80 \pm 3.7 \mathrm{~g}$ at 4 weeks after surgery. By contrast, the SO group lost weight during the first 4 weeks $(15 \pm 2.5 \mathrm{~g})$ and then gained weight for the remainder of the study (final weight, 507.2 $\pm 14.93 \mathrm{~g}$ ). During the first 4 weeks following surgery, rats in the Obese group gained weight $(45.13 \pm 12.45 \mathrm{~g})$ and those in the Lean group gained weight $(25.47 \pm 10.84 \mathrm{~g})$.

The cumulative caloric intake in the RYGB group was significantly lower compared with that in the Obese control group $(\mathrm{P}<0.01)$, and was similar between the RYGB and Lean groups. Food efficiency was significantly lower in the RYGB group compared with that in the Obese and Lean groups during the assessment over $24 \mathrm{~h}(\mathrm{P}<0.01)$ (Fig. 1A and B).

RYGB decreases leptin resistance in obese rats. The plasma leptin levels are shown in Fig. 1C. Leptin levels in Obese rats were significantly higher compared with those in the lean rats $(\mathrm{P}<0.01)$ and those in RYGB rats were lower compared with those in $\mathrm{SO}$ rats $(\mathrm{P}<0.01)$, while they were similar in RYGB and Lean rats.

Lep-R gene expression in the Obese group was significantly lower compared with that in the Lean group $(\mathrm{P}<0.05)$, while that in the RYGB group was higher than that in the SO group $(\mathrm{P}<0.05)$, and the levels were similar between the Obese and $\mathrm{SO}$ groups (Fig. 2A).

The gene expression levels of the anorectic peptide POMC in the Obese group were significantly lower than those in the Lean group $(\mathrm{P}<0.001)$, while those in the RYGB group were significantly higher than those in the SO group $(\mathrm{P}<0.001)$ (Fig. 2B). By contrast, the expression of the orexigenic peptide NPY in the Obese group was higher than that in the Lean group $(\mathrm{P}<0.05)$, while that in the RYGB group was significantly lower than that in the SO group $(\mathrm{P}<0.01)$ (Fig. 2C).

RYGB inhibits the expression of hypothalamic PTPIB in obese rats. PTPN1 mRNA expression levels in the hypothalami of 
A

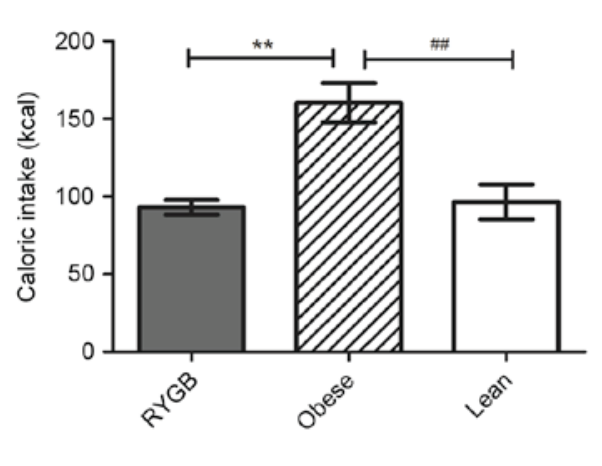

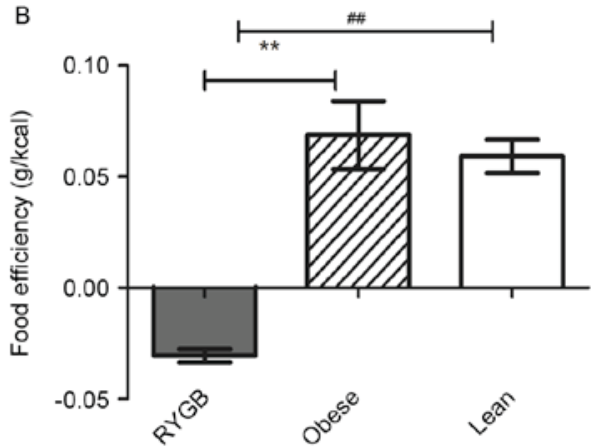

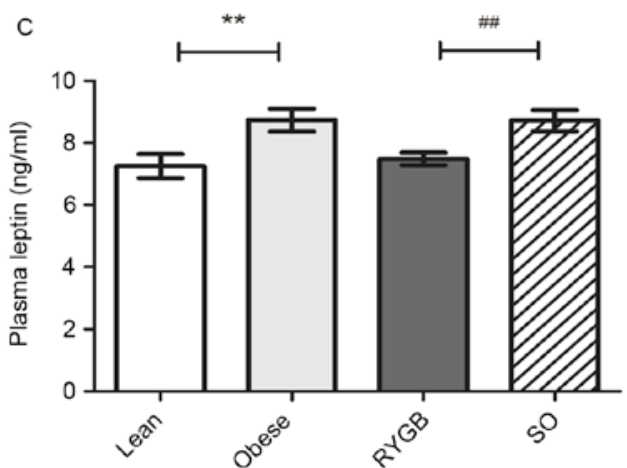

Figure 1. Daily food intake, food efficiency and plasma leptin. (A) Daily caloric intake was measured by re-feeding after fasting for $12 \mathrm{~h}$. (B) Food efficiency was calculated as change in weight in grams per kilocalorie of food consumed over the study period (24 h). (C) Plasma leptin levels. Values are expressed as the mean \pm standard error of the mean ( $\mathrm{n}=3$ in $\mathrm{A}$ and $\mathrm{B}$ and $\mathrm{n}=7$ in $\mathrm{C}$ ) ${ }^{* *} \mathrm{P}<0.01$, RYGB vs. Obese; ${ }^{\# \#} \mathrm{P}<0.01$, Obese vs. Lean. SO, sham operation; RYGB, Roux-en-Y gastric bypass.
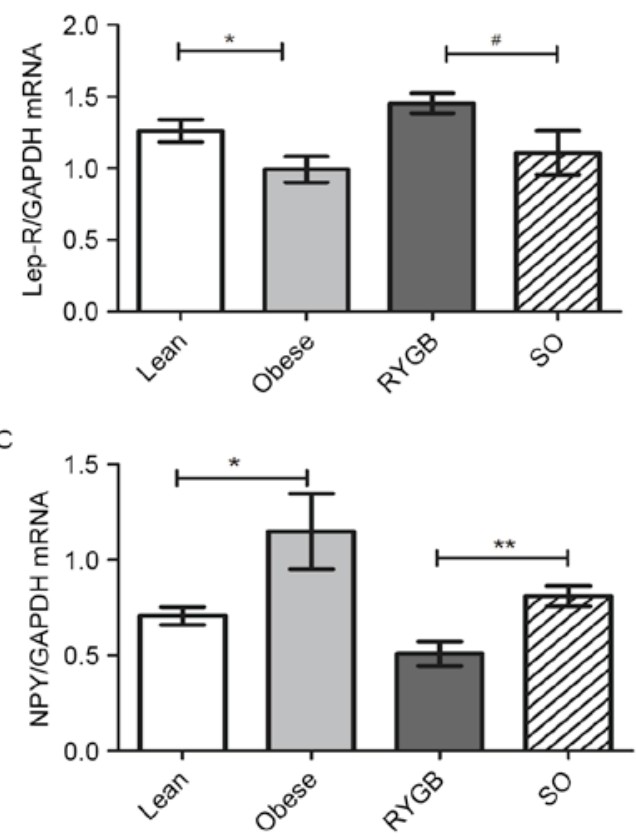
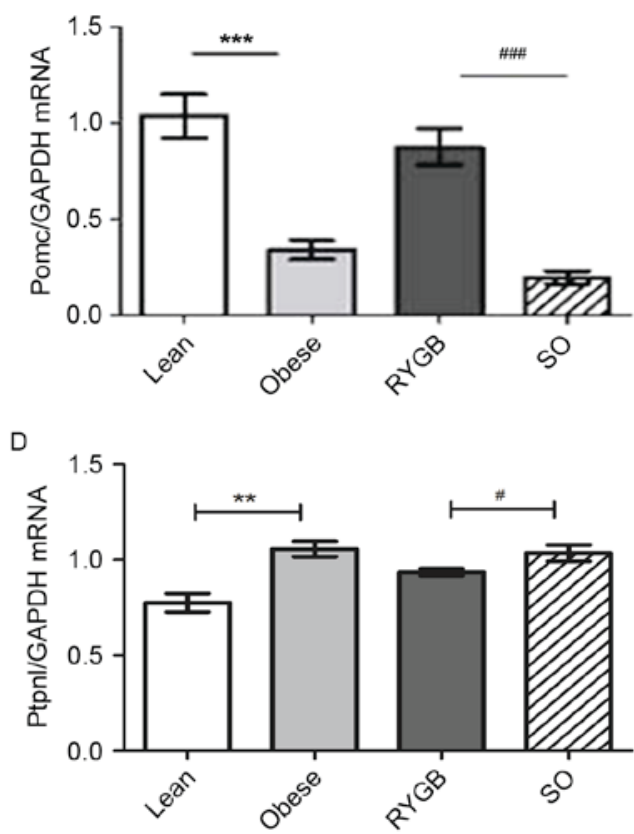

Figure 2. mRNA expression levels of leptin signaling pathway components and PTP1B in the hypothalamus. An endogenous control (GAPDH) was used to normalize the expression of the selected genes. Relative expression of (A) Lep-R, (B) POMC, (C) NYP and (D) PTPN1. Values are expressed as the mean \pm standard error of the mean ( $\mathrm{n}=4$ in $\mathrm{A}$ and $\mathrm{D}$ and $\mathrm{n}=6$ in $\mathrm{B}$ and $\mathrm{C}) .{ }^{*} \mathrm{P}<0.05,{ }^{* *} \mathrm{P}<0.01,{ }^{* * * *} \mathrm{P}<0.001$, Obese vs. Lean; ${ }^{\#} \mathrm{P}<0.05,{ }^{\# \#} \mathrm{P}<0.01,{ }^{\# \#} \mathrm{P}<0.001, \mathrm{RYGB}$ vs. SO (unpaired t-test). SO, sham operation; RYGB, Roux-en-Y gastric bypass; Lep-R, leptin receptor; POMC, proopiomelanocortin; NYP, Neuropeptide Y; PTPN1, protein tyrosine phosphatase 1B.

the Lean rats were significantly lower compared with those in Obese rats $(\mathrm{P}<0.01)$, while those in the RYGB group were lower compared with those in the SO group $(\mathrm{P}<0.05)$ (Fig. 2D).
PTP1B protein expression levels were significantly lower in the RYGB group compared with those in the $\mathrm{SO}$ group $(\mathrm{P}<0.05)$ and were similar to those in the Lean group (Fig. 3A). 
A
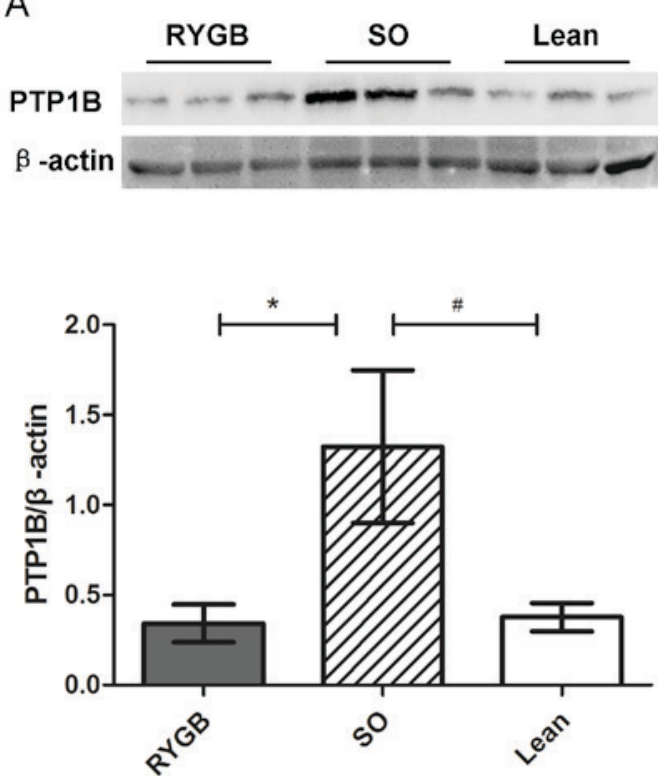

B
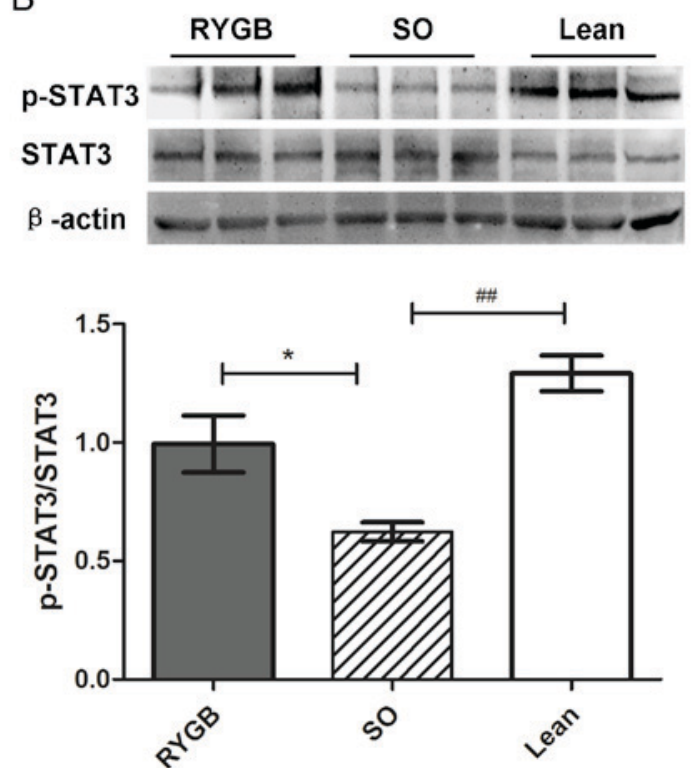

Figure 3. Protein expression levels of leptin signaling pathway components and PTP1B. The protein expression levels of leptin signaling pathway components and PTP1B in the hypothalamus. An endogenous control ( $\beta$-actin) was used to normalize the protein expression. (A) The protein levels of PTP1B in the RYGB group were significantly lower than those in the SO group $(\mathrm{P}<0.05)$, and similar to those in the Lean group. (B) The expression levels of $\mathrm{p}-\mathrm{STAT} 3$ in the RYGB group were significantly higher than those in the $\mathrm{SO}$ group $(\mathrm{P}<0.05)$ and similar to those in the Lean group, while the expression of STAT3 was similar in all groups. ${ }^{*} \mathrm{P}<0.05$, RYGB vs. SO; ${ }^{\#} \mathrm{P}<0.05,{ }^{\# \prime} \mathrm{P}<0.01$, SO vs. Lean. p-STAT3, phosphorylated signal transducer and activator of transcription; PTP1B, protein tyrosine phosphatase 1B; SO, sham operation; RYGB, Roux-en-Y gastric bypass.

RYGB leads to activation of $p$-STAT3 in obese rats. STAT3 is a key protein in the leptin pathway and p-STAT3 levels in the RYGB group were significantly higher than those in the SO group $(\mathrm{P}<0.05)$, while being similar to those in the Lean group. However, the total STAT3 expression did not differ between the groups (Fig. 3B).

\section{Discussion}

Obesity develops in leptin-resistant subjects with energy regulation defects. A major challenge in reversing the progressive deterioration of metabolic disturbances over time during obesity is to increase leptin sensitivity and promote energy expenditure to sustain normal body weight. Gastric bypass surgery reverses obesity or blocks its progression, leading to markedly reduced and sustained body weight loss in numerous morbidly obese patients (5). The present study investigated the role of specific obesity-associated molecules and tested whether their altered levels in obese rats were reversible by pronounced surgery-induced weight loss. The present study pursued a preliminary exploration of the potential weight loss mechanisms of RYGB surgery. The results indicated that weight loss was significant and may be associated with improvements in leptin resistance, and it should be involved the suppression PTP1B levels in the hypothalamus. Although the ability of RYGB to resolve obesity is well documented (28), few studies have assessed the exact underlying mechanisms. In the present study, notable changes occurred in leptin signaling activity and PTP1B levels in the hypothalamus. These findings clearly highlight the changes that occur in the hypothalamus following gastric bypass surgery in an obese rat model.

The present study observed significant body weight loss, accompanied by reduced caloric intake and improved food efficiency after RYGB surgery. Similar to the study by Borg et al (29), the present study supported the finding that hunger is reduced and satiety is increased after RYGB surgery. To accurately assess energy intake and utilization, food efficiency was evaluated. In the RYGB group, the food efficiency was significantly lower compared with that in the other groups. As previously reported, energy expenditure was improved after RYGB surgery (30). One of the factors that contributed to the improved food efficiency may be the browning of white fat. Brown adipose tissue activity has been reported to increase after weight loss (31). Another factor may be associated with the changes in brain activity, particularly in the hypothalamus. Molecular signals of adiposity, such as leptin and insulin, and gastrointestinal processes as well of other stimuli reflect the status of body fat storage and information transmitted to the hypothalamus. At present, functional changes in the hypothalamus following RYGB surgery are receiving an increased amount of attention from researchers (30).

Previous studies suggested that RYGB changes the appetite, including improved satiety and suppression of hunger. These changes were proved to be associated with hormonal changes, including leptin and ghrelin (32). In particular, increased leptin sensitivity may be a function of sustained weight loss following surgery. Consistent with the findings of previous studies $(32,33)$, the present study showed that leptin levels were elevated in obese rats and were decreased after RYGB. All of these findings suggest that leptin has a critical role in the development of obesity and weight loss after RYGB. The decreased leptin levels may result from the reduced fat content, while the possibility that increased leptin sensitivity inhibits its secretion in a feedback loop cannot be ruled out.

Leptin is a critical hormone for energy balance regulation, binds to Lep-R, and subsequently induces the 
phosphorylation of JAK2 and the activation of the STAT3 signaling pathway. As a major mediator of the effects of leptin, the JAK2/STAT3 pathway mediates adipose tissue-brain communication and provides a robust anorexigenic signal to the hypothalamus for the maintenance of energy homeostasis and normal body weight $(13,34)$. Defective leptin signaling in the hypothalamus prevents input to the anorexigenic areas by the adiposity negative feedback loop, and thus enhances food intake. Similar to previous studies (35), the present study observed that the serum levels of these hormones were increased in parallel with the resistance to receptor-mediated signaling in obese rats, suggesting that the obese model rats were in a state of leptin resistance. However, in the present study, serum leptin levels were decreased and the leptin signaling activity marker p-STAT3, a transcription factor that is commonly used as a marker of Lep-Rb-mediated neuronal activation (36), was upregulated. Moreover, the mRNA expression of the anorectic peptide POMC in RYGB rats was significantly increased compared with that in the SO group, while the expression of the orexigenic peptide NPY was decreased. Thus, it is indicated that the leptin resistance was reduced in obese rats after RYGB surgery. Two potential mechanisms may account for this. First, obesity is closely associated with a chronic and low-grade inflammatory state, which interrupts leptin signaling (37). After surgery, inflammation was alleviated, which may have led to the recovery of the signaling transduction, which remains to be demonstrated in future studies. In addition, the increased leptin receptor expression observed in the rat hypothalami after RYGB may have had a partial role.

Genetic and biochemical evidence for the role of PTP1B as a negative regulator of insulin and leptin-induced metabolic actions has emerged in recent years. PTP1B has been implicated in the development of cellular leptin and insulin resistance $(15,38)$. Thus, the present study examined PTP1B levels in obese model rats, showing that PTP1B was elevated in their hypothalamic tissues, similar to the findings of a previous study (20). A study by Chiarreotto-Ropelle et al (39) showed that physical exercise reduced hypothalamic PTP1B protein levels, and this reduction was partially associated with insulin and leptin sensitivity restoration. In accordance with these findings, it may be hypothesized that PTP1B has a role in the process of leptin resistance resolution after RYGB surgery. As expected, RYGB surgery effectively reduced hypothalamic PTP1B in obese rats and enhanced leptin signaling activity in the present study. According to these results, the RYGB surgery led to the downregulation of PTP1B expression and the improvement of leptin signaling activity due to decreasing the effects of PTP1B on the leptin signaling cascade. However, the exact mechanisms by which RYGB regulates the expression of PTP1B remain to be elucidated, which will be assessed in future studies. However, the present study proved that RYGB surgery suppresses hypothalamic PTP1B protein levels and alleviates leptin resistance, thereby providing a basis for further studies.

Leptin is a critical adipokine that regulates food intake and energy expenditure via hypothalamic signaling. During the development of obesity, this balance is interrupted and numerous metabolic parameters are dysregulated. In the present study, energy regulation was shown to be significantly improved by RYGB through the restoration of leptin sensitivity. As this result was associated with reduced PTP1B expression in the hypothalamus, this may be one mechanism responsible for the sustained weight loss and normalization of obesity-associated parameters after RYGB surgery. The underlying mechanisms of RYGB surgery will be further assessed by future studies.

\section{Acknowledgements}

The present study was supported by research grants from the Project of National Clinical Key Specialties Construction of China (2011), the Natural Science Foundation of Chongqing (no. CSTC2012jjA10040) and the Tackling Project of Science and Technology of Chongqing Committee of Science and Technology (no. CSTC2012ggyyjs10038).

\section{References}

1. Xu S and Xue Y: Pediatric obesity: Causes, symptoms, prevention and treatment. Exp Ther Med 11: 15-20,2016.

2. Rillamas-Sun E, LaCroix AZ, Waring ME, Kroenke $\mathrm{CH}$, LaMonte MJ, Vitolins MZ, Seguin R, Bell CL, Gass M, Manini TM, et al: Obesity and late-age survival without major disease or disability in older women. JAMA Intern Med 174: 98-106, 2014.

3. Colquitt JL, Pickett K, Loveman E and Frampton GK: Surgery for weight loss in adults. Cochrane Database Syst Rev 8: CD003641, 2014.

4. Mingrone G, Panunzi S, De Gaetano A, Guidone C, Iaconelli A, Nanni G, Castagneto M, Bornstein S and Rubino F: Bariatric-metabolic surgery versus conventional medical treatment in obese patients with type 2 diabetes: 5 year follow-up of an open-label, single-centre, randomised controlled trial. Lancet 386: 964-973, 2015.

5. Kassam Z, Smith M and Alm E: Bariatric surgery versus intensive medical therapy for diabetes. N Engl J Med 371: 680, 2014.

6. Puzziferri N, Roshek TB III, Mayo HG, Gallagher R, Belle SH and Livingston EH: Long-term follow-up after bariatric surgery: A systematic review. JAMA 312: 934-942, 2014.

7. Wickremesekera K, Miller G, Naotunne TD, Knowles G and Stubbs RS: Loss of insulin resistance after Roux-en-Y gastric bypass surgery: A time course study. Obes Surg 15: 474-481, 2005.

8. Adams TD, Gress RE, Smith SC, Halverson RC, Simper SC, Rosamond WD, Lamonte MJ, Stroup AM and Hunt SC: Long-term mortality after gastric bypass surgery. N Engl J Med 357: 753-761, 2007.

9. Buchwald H and Oien DM: Metabolic/bariatric surgery worldwide, 2011. Obes Surg 23: 427-436, 2013.

10. Halmi KA, Mason E, Falk JR and Stunkard A: Appetitive behavior after gastric bypass for obesity. Int J Obes 5: 457-464, 1981.

11. Elmquist JK, Elias CF and Saper CB: From lesions to leptin: Hypothalamic control of food intake and body weight. Neuron 22: 221-232, 1999.

12. Zhang Y, Proenca R, Maffei M, Barone M, Leopold L and Friedman JM: Positional cloning of the mouse obese gene and its human homologue. Nature 372: 425-432, 1994.

13. Elmquist JK, Maratos-Flier E, Saper CB and Flier JS: Unraveling the central nervous system pathways underlying responses to leptin. Nat Neurosci 1: 445-450, 1998.

14. Elias CF, Aschkenasi C, Lee C, Kelly J, Ahima RS, Bjorbaek C, Flier JS, Saper CB and Elmquist JK: Leptin differentially regulates NPY and POMC neurons projecting to the lateral hypothalamic area. Neuron 23: 775-786, 1999.

15. Tsou RC and Bence KK: Central regulation of metabolism by protein tyrosine phosphatases. Front. Neurosci 6: 192, 2013.

16. Brown-Shimer S, Johnson KA, Lawrence JB, Johnson C, Bruskin A, Green NR and Hill DE: Molecular cloning and chromosome mapping of the human gene encoding protein phosphotyrosyl phosphatase 1B. Proc Natl Acad Sci USA 87: 5148-5152, 1990. 
17. Frangioni JV, Beahm PH, Shifrin V, Jost CA and Neel BG: The nontransmembrane tyrosine phosphatase PTP-1B localizes to the endoplasmic reticulum via its 35 amino acid C-terminal sequence. Cell 68: 545-560, 1992.

18. Zabolotny JM, Bence-Hanulec KK, Stricker-Krongrad A, Hai F, Wang Y, Minokoshi Y, Kim YB, Elmquist JK, Tartaglia LA, Kahn BB and Neel BG: PTP1B regulates leptin signal transduction in vivo. Dev Cell 2: 489-495, 2002.

19. Myers MP, Andersen JN, Cheng A, Tremblay ML, Horvath CM, Parisien JP, Salmeen A, Barford D and Tonks NK: TYK2 and JAK2 are substrates of protein-tyrosine phosphatase 1B. J Biol Chem 276: 47771-47774, 2001.

20. White CL, Whittington A, Barnes MJ, Wang Z, Bray GA and Morrison CD: HF diets increase hypothalamic PTP1B and induce leptin resistance through both leptin-dependent and -independent mechanisms. Am J Physiol Endocrinol Metab 296: E291-E299, 2009.

21. Picardi PK, Calegari VC, Prada PO, Moraes CJ, Araújo E, Marcondes MC, Ueno M, Carvalheira JB, Velloso LA and Saad MJ: Reduction of hypothalamic protein tyrosine phosphatase improves insulin and leptin resistance in diet-induced obese rats. Endocrinology 149: 3870-3880, 2008.

22. Bence KK, Delibegovic M, Xue B, Gorgun CZ, Hotamislligil GS, Neel BG and Kahn BB: Neuronal PTP1B regulates body weight, adiposity and leptin action. Nat Med 12: 917-924, 2006

23. Hao Z, Munzberg H, Rezai-Zadeh K, Keenan M, Coulon D, Lu H, Berthoud HR and Ye J: Leptin deficient ob/ob mice and diet-induced obese mice responded differently to Roux-en-Y bypass surgery. Int J Obes (Lond) 39: 798-805, 2015.

24. Maffei M, Halaas J, Ravussin E, Pratley RE, Lee GH, Zhang Y, Fei H, Kim S, Lallone R, Ranganathan S, et al: Leptin levels in human and rodent: Measurement of plasma leptin and ob RNA in obese and weight-reduced subjects. Nat Med 1: 1155-1161, 1995.

25. Lima MM, Pareja JC, Alegre SM, Geloneze SR, Kahn SR, Kahn SE, Astiarraga BD, Chaim EA and Geloneze B: Acute effect of Roux-en-y gastric bypass on whole-body insulin sensitivity: A study with the euglycemic-hyperinsulinemic clamp. J Clin Endocrinol Metab 95: 3871-3875, 2010.

26. Lima MM, Pareja JC, Alegre SM, Geloneze SR, Kahn SE, Astiarraga BD, Chaim ÉA and Geloneze B: Visceral fat resection in humans: Effect on insulin sensitivity, beta-cell function, adipokines, and inflammatory markers. Obesity (Silver Spring) 21 E182-E189, 2013.

27. Livak KJ and Schmittgen TD: Analysis of relative gene expression data using real-time quantitative PCR and the 2(-Delta Delta C(T)) Method. Methods 25: 402-408, 2001
28. Buchwald H, Buchwald JN and McGlennon TW: Systematic review and meta-analysis of medium-term outcomes after banded Roux-en-Y gastric bypass. Obes Surg 24: 1536-1551, 2014.

29. Borg CM, le Roux CW, Ghatei MA, Bloom SR, Patel AG and Aylwin SJ: Progressive rise in gut hormone levels after Roux-en-Y gastric bypass suggests gut adaptation and explains altered satiety. Br J Surg 93: 210-215, 2006.

30. Zheng H, Shin AC, Lenard NR, Townsend RL, Patterson LM, Sigalet DL and Berthoud HB: Meal patterns, satiety, and food choice in a rat model of Roux-en-Y gastric bypass surgery. Am J Physiol Regul Integr Comp Physiol 297: R1273-R1282, 2009.

31. Vijgen GH, Bouvy ND, Teule GJ, Brans B, Hoeks J, Schrauwe P and van Marken Lichtenbett WD: Increase in brown adipose tissue activity after weight loss in morbidly obese subjects. J Clin Endocrinol Metab 97: E1229-E1233, 2012.

32. Terra X, Auguet T, Guiu-Jurado E, Berlanga A, Orellana-Gavaldà $J M$, Hernández $M$, Sabench $F$, Porras JA, Liutart J, Martinez S, et al: Long-term changes in leptin, chemerin and ghrelin levels following different bariatric surgery procedures: Roux-en-Y gastric bypass and sleeve gastrectomy. Obes Surg 23: 1790-1798, 2013.

33. Pedersen SD: The role of hormonal factors in weight loss and recidivism after bariatric surgery. Gastroenterol Res Pract 2013: 528450,2013

34. Friedman JM and Halaas JL: Leptin and the regulation of body weight in mammals. Nature 395: 763-770, 1998.

35. Hankir MK, Ashrafian H,Hesse S, Horstmann A and Fenske WK: Distinctive striatal dopamine signaling after dieting and gastric bypass. Trends Endocrinol Metab 26: 223-230, 2015.

36. Myers MG Jr: Leptin receptor signaling and the regulation of mammalian physiology. Recent Prog Horm Res 59: 287-304, 2004.

37. Balland E and Cowley MA: New insights in leptin resistance mechanisms in mice. Front Neuroendocrinol 39: 59-65, 2015.

38. Lund IK, Hansen JA, Andersen HS, Møller NP and Billestrup N: Mechanism of protein tyrosine phosphatase 1B-mediated inhibition of leptin signalling. J Mol Endocrinol 34: 339-351, 2005.

39. Chiarreotto-Ropelle EC, Pauli LS, Katashima CK, Pimentel GD, Picardi PK, Silva VR, de Souza CT, Prada PO, Cintra DE, Cavalheira JB, et al: Acute exercise suppresses hypothalamic PTP1B protein level and improves insulin and leptin signaling in obese rats. Am J Physiol Endocrinol Metab 305: E649-E659, 2013. 